\title{
Archivists as amanuenses (scribes) of Indigenous knowledge*
}

\section{Nicola Laurent}

This article uses the Return, Reconcile, Renew: understanding the history, effects and opportunities of repatriation and building an evidence base for the future project as a case study to explore the collaborative relationship between the eScholarship Research Centre and the community partners, representative organizations of the Ngarrindjeri, the Torres Strait and the Kimberley Indigenous communities. Drawing on interviews with Return, Reconcile, Renew project archivists, it explores archival issues - across the four themes of collaboration, space, time and place, neutrality and access - relating to Indigenous cultural heritage and working with Indigenous communities to make materials and knowledge accessible in culturally appropriate ways. Within the context of community rights to cultural knowledge, this paper will discuss the ongoing obligations of organizations working with Indigenous communities and records.

"As archivists we are privileged that we are given access and are allowed to learn about Indigenous knowledge. We don't have the authority or right to teach it to others." (Archivist, Return, Reconcile, Renew project, 2017)

This article summarizes the semi-structured interviews undertaken with three archivists who work on the Return, Reconcile, Renew: understanding the history, effects and opportunities of repatriation and building an evidence base for the future project and discusses the issues raised across the four themes of collaboration, space, time and place, neutrality and access. It is of primary relevance to archivists and information professionals who might be considering, or are already working with Indigenous communities. However, the subjects discussed have value beyond those solely working with Indigenous communities, and this article will explore the themes' relevance in other archival contexts through the author's own work on the Find \& Connect web resource. ${ }^{1}$

Return, Reconcile, Renew started in 2013 as an Australian Research Council funded linkage project headed by Australian National University's National Centre for Indigenous Studies

Nicola Laurent is a Project Archivist on the Find \& Connect web resource team, eScholarship Research Centre, University of Melbourne. She is the Vice-President of the Australian Society of Archivists and was a 2016 recipient of the International Council of Archives New Professional bursary.

1 Funded by the Australian Government, Find \& Connect is a web resource for Forgotten Australians, Former Child Migrants, members of the Stolen Generations, and anyone interested in the history of child welfare in Australia, https://findandconnect.gov.au/ (viewed 1 March 2018). 
Nicola Laurent

* This article is based on a conference paper given at the ICA Section on University and Research Institution Archives Conference in Latvia, August 2017. I want to thank the members of the Return, Reconcile, Renew team who assisted during the process of writing this article for their time, expertise, support and constructive comments and suggestions.

https://doi.org/10.3828/comma.2017.2.5

and led by Chief Investigator Associate Professor Cressida Fforde. ${ }^{2}$ The aim of the project is to advance repatriation of Ancestral Remains research, support ongoing repatriation efforts by Indigenous communities through the resources created and to educate collecting institutions and the public for reconciliation purposes. ${ }^{3}$ The project collates existing traditional Indigenous knowledge with research and literature gathered by researchers since the 1990s into a database that records the history and effects of the removal and repatriation of Ancestral Remains of the three Australian partner Indigenous organizations: the Kimberley Aboriginal Law and Culture Centre (KALACC); the Ngarrindjeri Regional Authority (NRA); Gur A Baradharaw Kod Torres Strait Sea and Land Council (GBK). Return, Reconcile, Renew has a significant and diverse number of partners with experience in repatriation research and practice. ${ }^{4}$

Outputs of the Return, Reconcile, Renew project include the creation of a digital archive of available materials collated from existing knowledge. Indigenous communities hold secret and sacred knowledge that only certain members of the community can access. The digital archive needed to represent the communities' views and values on information sharing and access and this required the archive to hold public, private and restricted information. ${ }^{5}$ It was determined early in the project that any information about Ancestral Remains from a particular community is private knowledge and can only be accessed by that Indigenous community partner organization. Therefore, the outputs would need to be a separate, private database for each community partner organization.

2 More information about the Return, Reconcile, Renew project at http://esrc.unimelb.edu.au/projects/ return-reconcile-renew; http://ncis.anu.edu.au/research/heritage_history_repatriation.php; http://aiatsis. gov.au/research/research-themes/languages-and-cultural-expression/arc-repatriation-linkagereturn-reconcile-renew (all viewed 5 March 2018).

${ }^{3}$ Further information on the repatriation of Indigenous Ancestral Remains can be found at: TURNBULL Paul, 'Managing and mapping the history of collecting indigenous human remains' in Australian Library Journal, 65:3, 2016, 203-212 and AUSTRALIAN DEPARTMENT OF COMMUNICATIONS AND THE ARTS, 'Australian Government Policy on Indigenous Repatriation', 2016 (viewed 5 June 2018).

4 The Indigenous partners on the project are the Kimberley Aboriginal Law and Culture Centre (KA LACC), the Ngarrindjeri Regional Authority (NRA), Gur A Baradharaw Kod Torres Strait Sea and Land Council (GBK), and from North America, the Association of American Indian Affairs (AAIA). The University of Melbourne, University of Tasmania, University of Otago and Flinders University are involved from the education sector, while Government partners include The Australian Institute of Aboriginal and Torres Strait Islander Studies (AIATSIS), Ministry for the Arts (Department of Communication and the Arts), National Museum of Australia and Museum of New Zealand Te Papa Tongarewa.

${ }^{5} \mathrm{KOCH}$ Grace, 'Ethics and research: dilemma raised in managing research collections of Aboriginal and Torres Strait Islander materials' in Australian Aboriginal Studies, 2, 2010, pp. 48-59. 
Each database includes all public data, and relevant private and restricted data for that community partner organization. Each community's database will be provided to them in print form (as a PDF copy of the offline HTML), in digital PDF, the XML files and if they choose, the relational database itself. Data deemed appropriate for the general public will be available as a web resource. The publicly available web resource will consolidate the perspectives and knowledge of repatriation of Ancestral Remains for educational and advocacy purposes. ${ }^{6}$

The concept of "Archivists as amanuenses or scribes of Indigenous knowledge" used in this article was inspired by the agreement between the Ngarrindjeri Regional Authority and other project partners. The Ngarrindjeri required the acceptance of a very explicit agreement before signing onto the project, making it clear they own the intellectual property over their knowledge. 7 Therefore no Indigenous knowledge contributed from the community can be published without their permission and without appropriate acknowledgments. Vital to the project's successful start was the understanding that its archivists could document the knowledge, but ownership would remain with the relevant community.

In order to ensure a productive project, it was critical that the archivists formed collaborative relationships with the Indigenous representatives, enabling them to work with traditional Indigenous knowledge that would otherwise remain private. I conducted semi-structured interviews with the three archivists based at the eScholarship Research Centre of The University of Melbourne, an approach which allowed the participants to expand upon the questions they felt most important, share any knowledge they felt missing, while ensuring that specific information was gathered from all three. ${ }^{8}$ The archivists interviewed were Associate Professor Gavan McCarthy, Director of the eScholarship Research Centre and a Chief Investigator on the project; Ailie Smith, a Senior Research Archivist; and Annelie de Villiers, Assistant Research Archivist, who curate, collate and collect the information for the archive and databases. The interviews explored issues relating to Indigenous cultural heritage and working with Indigenous communities to make materials and knowledge accessible in culturally appropriate ways.

During the interviews it became apparent that many of the issues discussed were not solely about or for Indigenous archives. Thus the lessons learnt have been broadened out, showing parallels when working with other community

\footnotetext{
${ }^{6}$ See MCCARTHY Gavan, SMITH Ailie and DE VILLIERS Annelie, 'Repatriation knowledge in the networked archive of the twenty-first century' in FFORDE Cressida, KEELER Honor and MCKEOWN Tim (eds) The Routledge Companion to Indigenous Repatriation: Return, Reconcile, Renew, Routledge, forthcoming.

${ }^{7}$ HEMMING Steve, RIGNEY Daryle and BERG Shaun, 'Researching on Ngarrindjeri Ruwe/Ruwar: Methodologies for positive transformation' in Australian Aboriginal Studies, 2, 2010, 92-106.

8 Interview method from WILLIAMSON Kirsty, 'Ethnographic Research' in WILLIAMSON Kirsty and JOHANSON Graeme (eds) Research methods: information, systems and contexts, Tilde Publishing, Prahran, 2013, 361-363.
} 
groups and highlighting the "takeaways" to be applied whenever work is undertaken with any individuals or community groups. ${ }^{9}$

For this article, my experiences as a Project Archivist on the Find \& Connect web resource will be used to explore how the lessons learned with Indigenous groups can be applied, in particular, to Care Leaver communities. A Care Leaver is someone who spent time in out-of-home care, for example, in orphanages and children's homes, as a child. Find \& Connect is a web resource designed to help connect people to their past in "care", documenting the history of child welfare in Australia, including what records exist, where those records are held and how to access them. ${ }^{10}$

\section{Collaboration}

The first theme to emerge from the interviews is the importance of a collaborative relationship. Collaboration is at the root of all work on the Return, Reconcile, Renew project and all interviewees discussed what they had learnt about forging collaborative relationships with a community group.

Most importantly, collaboration needs to start at the beginning of any project; it needs to be included in the project design. In accordance with participatory research methodology, the community group should be equal partners throughout the life of the project, included from research design to dissemination of findings. ${ }^{11}$ Indigenous Australians are perceived as some of the most researched communities in the world and previous research relationships may have been exploitative and were commonly conducted inappropriately. ${ }^{12}$ Trust is a key requirement in any new research relationship, but requires an investment of time and energy. ${ }^{13}$

One of the archivists repeated that overpromising and sometimes underdelivering could irreparably damage the relationship; expectation management

\footnotetext{
${ }^{9}$ Participatory models of research emphasize that the individuals or community involved are more than just a subject and should be participating as equals in any processes, including decision-making. See, for example, GILLILAND Anne and MCKEMMISH Sue, 'The role of participatory archives in furthering human rights, reconciliation and recovery' in Atlanti: Review for Modern Archival Theory and Practice, 24, 2014, 78-88. NICHOLLS Sophie, BOOKER Lauren, THORPE Kirsten, JACKSON Melissa, GIRA ULT Clement, BRIGGS Ronald and JONES Caroline, 'From principles to practice: community consultation regarding access to Indigenous language material in archival records at the State Library of New South Wales' in Archives and Manuscripts, 44:3, 2016, 110-123. CASWELL Michalle, 'Toward a Survivor-Centered Approach to Human Rights Archives: Lessons from Community-Based Archives' in Archival Science, 14:3-4, 2014, 307-322. 10 Find \& Connect website, at https://findandconnect.gov.au/about/, viewed 22 March 2018. O'NEILL Cate, 'Forgotten Australians in the library: resources relating to Care Leavers in Australian libraries' in The Australian Library Journal, 65:3, 2016, pp. 181-190.

11 MCKEMMISH Sue, BURSTEIN Frada, MANASZEWICZ Rosetta, FISHER Julie and EVANS Joanne, 'Inclusive research design' in Information, Communication \& Society, 15:7, 2012, pp. 1106-1135.

12 SMITH Linda Tuhiwai, Decolonizing Methodologies: Research and Indigenous Peoples, 2nd ed., Zed Books, London, 2012.

13 Research Outcomes Part 3: Implications for Researchers and Educators in Koorie Archiving: Trust and Technology - Final Report, https://www.monash.edu/it/our-research/researchcentres-and-labs/cosi/projects/ completed-projects/trust/final-report/research-outcomespart-3 (viewed 26 March 2018).
} 
needs to occur from the beginning. Whenever possible, it is essential to build time and funding into the project for relationship building. One archivist emphasized that once a relationship has been formed, it should not be assumed that it will last: time and resources need to be allocated to continually work on the relationship. It is also essential to be flexible with the project plan. Another archivist noted the importance of being prepared to respond to the needs of the community as necessary, and to run with what needs to happen or any variables that pop up, instead of rigidly sticking to the original project plan.

The priorities for any project related to community groups is to focus on how it will help the community, and to be driven by that community's specific needs and requirements. ${ }^{14} \mathrm{~A}$ technique for ensuring successful engagement is to think of and treat everyone involved as a researcher, as an equal partner in the project. All interviewees emphasized that there was no need to be an academic to be considered "a researcher". For Return, Reconcile, Renew, the community group has provided leadership to the archivists and their work by providing guidance on what is most beneficial to them. One archivist stated the importance of never going into the community with definitive answers, recognizing that this is not your knowledge and that here, the community is the expert; instead go in with the understanding that there needs to be a collaborative process where everyone learns together.

Capacity for engagement and collaboration must be built into the project plan. Return, Reconcile, Renew project employs action research methodology which allows for regular face-to-face meetings, workshops, teleconferences and visits to the community. (The same approach was also taken by Find \& Connect's predecessor, the Who Am I project, where it was made clear the Care Leavers involved were the experts, the ones with the lived experience while everyone else involved was learning from them.) ${ }^{15}$

In Return, Reconcile, Renew, the archivists have taken direction on all decisions from representatives within the community groups, on everything from the language used in the databases, to what knowledge is private or public, and to how the data is structured. Constant open dialogue has ensured that the communities are represented in the way they want; this includes representing the information differently for each community. When working with community groups, a key slogan, and one which originated among disability activists is "Nothing about us, without us." This resonates among many communities,

\footnotetext{
14 The AIATSIS (Australian Institute of Aboriginal and Torres Strait Islander Studies) Guidelines for Ethical Research in Australian Indigenous Studies were created 'to ensure that research with and about Aboriginal and Torres Strait Islander peoples followed a process of meaningful engagement and reciprocity between the researcher and the individuals and/or communities involved in the research' https://aiatsis.gov.au/research/ ethical-research/guidelines-ethicalresearch-australian-indigenous-studies, 2012 (viewed 13 June 2018).

15 HUMPHREYS Cathy and KERTESZ Margaret, "Putting the heart back into the record" personal records to support young people in care' in Adoption and Fostering, 36:1, 2012, 27-39. HUMPHREYS Cathy, MCCARTHY Gavan, DOWLING Melissa, KERTESZ Margaret and TROPEA Rachel, 'Improving the archiving of records in the out-of-home care sector' in Australian Social Work, 67:4, 2014, 509-524.
} 
Nicola Laurent

including Care Leavers, who use it to ensure they are represented in any decisions relevant to them. ${ }^{16}$

\section{Place, time and space}

The second theme was the significance of physical place, space and time to the research: the phrase "Doing data on Country" came up repeatedly during the interviews. ${ }^{17}$ One archivist stated going onto Country to complete data entry allowed you to become absorbed into your surroundings, see the areas being talked about, learn the language to use, understand the space you are working in, and therefore know how to talk appropriately about the data recorded in, and when recording it in the database. For example, on one visit to an Indigenous community the team noticed posters on the walls that documented past repatriation efforts. These posters were on display because the community were proud of the way they portrayed the message of repatriation; this understanding could then be fed into the database.

Visiting the Indigenous communities on their Country also meant that rather than just meeting one or two representatives of the community, the project team had the opportunity to interact with the broader community. Visits thus enabled the community to engage with the project, ensuring there were opportunities for "Nothing about us, without us" to be enacted. Going onto Country assisted in creating a trusting relationship and provided the archivists the opportunity to introduce themselves, explain why they needed access to the community's records and the significant value of the community's input. It was essential to build up trust to gain community involvement and going onto Country was one way of achieving that.

All interviewees highlighted the importance and difficulties of creating and maintaining a long-term relationship with communities, particularly outside specific project goals. Challenges are faced around structurally embedding these relationships within organizations, relationships which cannot just be based on a connection between individuals, while organizations continually face budget, time and staffing constraints. One archivist noted the importance of maintaining and developing any relationships formed as it means the communities are less likely to be the subject of separate short-term projects, and a continuing relationship can make for easier initiation of future mutually beneficial projects.

16 https://en.wikipedia.org/wiki/Nothing_About_Us_Without_Us, viewed on 5 March 2018; GOLDING Frank, 'Nothing about us without us', http://frankgolding.com/nothing-about-uswithout-us/ (viewed on 28 March 2018).

17 On Country is "A term used by Aboriginal Australians to refer to being on the Land to which they belong and their place of Dreaming. Aboriginal English usage of the word 'Country' is much broader than standard English. In an Aboriginal context, it is often written with an upper case," p.17 in WALANGA MURU and MAQUARIE

STATE UNIVERSITY, Aboriginal cultural protocols, 2016. See also DE VILLIERS Annelie, 'Doing fieldwork in Indigenous communities' in The 30 Second Archive blog, https://30secondarchive.wordpress.com/2017/05/16/doing-fieldwork-in-indigenouscommunities/ (viewed 6 April 2018). 
Archivists as amanuenses (scribes) of Indigenous knowledge

From an archival perspective, having an ongoing relationship can create a more open conversation around access and give the community additional control over their material in the archive. Improved communication makes it much easier to consult the relevant community before working on any material about or relevant to them. However, there are ongoing obligations to the community once a partnership is established, and if the relationship is to be maintained. This upkeep could require ongoing work at unexpected times and a need to respond promptly to issues that arise over time: one example is where the community becomes aware of now inappropriate language being used in an old finding aid.

The importance of articulating project outcomes in ways that highlight the benefit to the communities, rather than just the stated, often long-term and less immediately relevant, research goals, was evident within the interviews. In the past, there have been instances of researchers going into communities (sometimes with promises for improvements), achieving their project outcomes and then leaving, with the persons or group involved left in the same position they were before. For example, in discussing her experiences as a child who grew up in out-of-home care, Jacqueline Wilson recalls being regularly interviewed by researchers (among others), who she spoke willingly with, based on the implied understanding, or explicit statements from the interviewers, that they would "provide support" or benefit her and others in similar situations. ${ }^{18}$ The researchers meant potential future policy changes, whereas Wilson expected actual support and help on a personal level immediately. One archivist stated the importance of being realistic about what the research or project can achieve and communicating that effectively and clearly with the community.

Alongside the organizations' ongoing obligation, two archivists noted a personal obligation to the community: "once you become entangled with the records and archives of people, you become entangled for life". One explained that it is not appropriate to involve yourself with personal records of people's lives and then just forget about them once the money ends. Both concluded that it is easy to forget the human element of archives, and just see the paper in boxes, but they represent human lives and tell a person's story. As archivists, we have obligations to the people, and to the records, to treat them appropriately and with compassion.

One interviewee stated that the importance of listening was the most important skill learnt while working on Return, Reconcile, Renew; listening enabled the Indigenous collaborators not just to tell their story but to direct where the project is going. The non-Indigenous participants must be open to discussion and understanding a different way of thinking. It is important not go in as "the expert"; in the context of an unfamiliar culture, you aren't one; it is your expertise as an archivist that is wanted. Project meetings were run with much deeper levels of engagement than might normally take place in project meetings: it was not appropriate to have strictly enforced and timed agendas,

18 WILSON Jacqueline Z., MENDES Philip and GOLDING Frank, 'Hope Street: from voice to agency for care-leavers in higher education' in Life Writing, 15:4, 2018, 597-609. 
for example, that would limit discussions. Instead a more relaxed approach was taken, with a few examples taken into a meeting as discussion points and conversation allowed to run for as long as necessary. The team found that often the community's first impressions changed, the more time they had to ask questions and engage with the team. Future projects would need to allocate time for this process to occur.

\section{Never neutral}

The third theme to emerge from the interviews was that working on the Return, Reconcile, Renew project highlighted how archival methods, systems and principles (and us as archivists) are not neutral, and that we therefore need to continually challenge and change the practices and processes in place.

The systems and principles on which archives are based are biased towards western culture - the way western society operates and its values. ${ }^{19}$ One archivist observed that, often the fundamental principles themselves are not wrong, it is the ways in which they have been articulated over time that are problematic. As another interviewee commented:

Every decision you make you are either continuing to colonize or actively decolonizing. One needs to engage consciously. Do not just accept policy or terminology without engaging with it critically, it is about reflective research, be a reflective researcher/practitioner. Consider your own bias and prejudices and that of your organization and that of your archival system and research methodology.

Such practices align with recent literature and guidelines on decolonising the archives..$^{20}$ In the same way, the need to change the language traditionally used by information professionals and to not replicate original descriptions or categories if they do not represent the values of the Indigenous communities involved was a prominent feature of all the interviews. In the case of Return, Reconcile, Renew this has meant incorporating Indigenous languages into the databases and on the public web resource, one instance being the use of Indigenous place names over the more commonly used Western names.

19 SENTANCE Nathan, 'Your neutral is not our neutral', in Archival Decolonist, https://archivaldecolonist. com/2018/01/18/your-neutral-is-not-our-neutral/, 18 Jan. 2018 (viewed 31 March 2018).

${ }^{20}$ For example, Aboriginal and Torres Strait Islander Library, Information and Resource Network (ATSILIRN), 'Aboriginal and Torres Strait Islander protocols for libraries, archives and information services', http://atsilirn.aiatsis.gov.au/protocols.php, 2012 (viewed 13 June 2018); ORMOND-PARKER Lyndon and SLOGGETT Robyn, 'Local archives and community collecting in the digital age' in Archival Science, 12:2, 2012, pp.191-212; THORPE Kirsten and GALASSI Monica, 'Rediscovering Indigenous languages: the role and impact of libraries and archives in cultural revitalisation' in Australian Academic \& Research Libraries, 45:2, 2014, pp. 81-100; LUKER Trish, 'Decolonising archives: Indigenous challenges to record keeping in "reconciling" settler colonial states' in Australian Feminist Studies, 32:91-92, 2017, pp. 108-125; FAULKHEAD Shannon, IACOVINO Livia, MCKEMMISH Sue and THORPE Kirsten, 'Australian Indigenous knowledge and the archives: embracing multiple ways of knowing and keeping' in Archives and Manuscripts, 38:1, 2010, pp. 27-50. 
Privileging people with lived experiences over archival principles and the traditional (Western) way of managing archives is one way in which the eScholarship Research Centre has dealt with issues around archival standards. In Return, Reconcile, Renew, Ancestral Remains are not referred to as museum "specimens" as they are commonly listed in museum catalogues. Instead, they are being recorded as people. On the Find \& Connect web resource we have decided to change the way we display historical, and now offensive, language, and in doing so, challenging the traditional archival concept of directly copying any titles or information included with the original record; at the same time, there is no compromising access. ${ }^{21}$

These approaches to archival principles extend to how archivists work with Indigenous knowledge. Some researchers of the past would record Indigenous knowledge, no matter if it was private or sacred, and document themselves as the only author and therefore "owner" of the knowledge.22 Much information exists in archives, libraries and museums that should be private, only known to the community, and often, to specific members of the community. ${ }^{23}$ Whilst such knowledge is now better protected by Indigenous cultural intellectual property laws, ${ }^{24}$ one archivist discussed the importance, within the context of Return, Reconcile, Renew, of archivists being aware of these past injustices so they do not facilitate easy access to such materials. Without the Indigenous community's knowledge contribution, the databases could have been skewed towards privileging the researchers, or the archivist's own knowledge, or, more generally, towards that of the collecting institutions due to the amount of historical information freely available about the practices. Instead the knowledge contained within the databases are equally representative of the Indigenous communities.

Contextual knowledge has also influenced who is documented as the author of entries on the web resource and content within the database. Historical practice across other resources created by the eScholarship Research Centre, is that, as a rule, whoever compiled that entry is recorded as the author. Instead, with Return, Reconcile, Renew, multiple contributions to individual entries are

\footnotetext{
21 WRIGHT Kirsten, 'Language and the words we use' in Find \& Connect web resource blog, www.fi ndandconnectwrblog.info/2017/09/language-and-the-words-we-use/, 8 Sept. 2017 (viewed 25 March 2018).

22 ANDERSON Jane, 'Access and control of Indigenous knowledge in libraries and archives: ownership and future use', in Correcting Course: Rebalancing Copyright for Libraries in the National and International Arena Program, http://correctingcourse.columbia.edu/paper_anderson.pdf, 2005 (viewed 2 April 2018).

${ }^{23}$ NAKATA Martin, BYRNE Alex, NAKATA Vicky and GARDINER Gabrielle, 'Indigenous knowledge, the library and information service sector, and protocols' in Australian Academic and Research Libraries, 36:2, 2005, p. 10.

${ }^{24}$ ARTS LAW CENTRE OF AUSTRALIA, 'Artists in the Black information sheet - Indigenous Cultural Intellectual Property
(ICIP)', https://www.artslaw.com.au/images/uploads/aitb/AITB_information_sheet__Indigenous_cultural_and_intellectual_property_ICIP_2.pdf, 2011 (viewed 31 March 2018). See also DAVIS Michael, 'Indigenous peoples and Intellectual Property Rights - Research Paper 20', https://www.aph.gov.au/About_Parliament/Parliamentary_Departments/Parliamentary_Librar y/pubs/rp/RP9697/97rp20, 1996-97 (viewed 2 April 2018).
} 
Nicola Laurent

acknowledged, and this is separate from who owns the knowledge, thus moving away from traditional Western understanding of authorship and ownership.

\section{Questioning access}

The fourth theme that appeared was the questioning and challenging of access principles within this project to ensure provision of culturally appropriate access to records, archives and knowledge. ${ }^{25}$ The reasons, and need, for the Return, Reconcile, Renew databases to be private until appropriate access regimes are agreed has been discussed above; here I will discuss the challenges in making them appropriately accessible.

The project has taken the approach of providing multiple representations of the information in the database. These multimodal outputs were chosen following consultation with the communities to ensure that those communities receive the information in the most relevant and user-friendly way. While this is likely to result in the print version being annotated, resulting in version control issues, this process also empowers the community by giving them the control to manage both the validity and access to the information in the most suitable way for them. Re-synchronising any annotations with the relational database could then become a batch job with a new edition of the outputs produced as required.

Questions around longevity have also driven the access decisions; digital files can be corrupted over time, access to computers and the internet can be limited, but paper survives passive neglect, unless disaster strikes, and it can be accessed without additional devices. In this project, having multiple access points to the same information is one way the archivists can ensure they are providing a sustainable resource and it affords the ability to transfer control of the materials to the communities.

As archivists we are privileged, and we need to use this privilege for good and support the communities whose records we hold. From my experiences on Find \& Connect we hear how archivists can see all the records related to a Care Leaver, while the person who is the subject of the record is not allowed access to all their files and those they can access will be redacted. The redactions are commonly completed by archivists due to third party privacy concerns but this has included removing everything down to parent's names, leaving the person confused and potentially traumatized about why they cannot access information about their own family, but the archivist can. ${ }^{26}$

In the case of Return, Reconcile, Renew the archivists are the only ones who know what is in all four databases. The archivists have seen all the references and therefore, more information, about the Ancestral Remains and the processes of repatriation than the Indigenous communities have, so the

${ }^{25}$ CHRISTEN Kimberly, 'Ara Irititja: protecting the past, accessing the future - Indigenous memories in a digital age. A digital archive project of the Pitjantjatjara Council', in Museum Anthropology, 29:1, 2008, pp. 56-60.

${ }^{26}$ JONES Michael and O'NEILL Cate, 'Identity, records and archival evidence: exploring the needs of Forgotten Australians and Former Child Migrants', in Archives \& Records, 35:2, 2014, pp. 113114. 
Archivists as amanuenses (scribes) of Indigenous knowledge

communities are placing a lot of trust in the archivists to do the right thing and not to abuse their power. A crucial way to repay that trust is by providing appropriate and long-lasting access for the people and communities who the records are about.

This article has addressed four themes that together create a good engagement experience: collaboration; the importance of physical space and time for research; awareness that archivists and archival principles and systems are not neutral; and the need to provide culturally appropriate access. Participating in the project has taught the three archivists involved to be more open in their thinking, to question the way they have always done things, to put more effort into the relationships created, to visit the collaborators on their Country, and to acknowledge that we are not always the experts - and indeed sometimes we are just scribes of other people's knowledge.

We need to remove the power and privilege archives and archivists have by being open about our own prejudices and those currently embedded within the principles and systems we use. Rather than just reproducing existing power structures, we need instead to challenge and change them by working collaboratively with community groups, empowering them to use and access their archives in the way most appropriate to them. 